\title{
MANAJEMEN PEMBELAJARAN SENI BACA ALQURAN DI PONDOK PESANTREN ALQURAN AL-ITQON BOGOR
}

\author{
Muhammad Abdurrahman Efendi $^{a)}$, M. Entang ${ }^{b)}$, Rais Hidayat ${ }^{b *}$, Dian Wulandari $^{b)}$ \\ a) SMK Alwatasi Caringin, Bogor, Indonesia \\ ${ }^{b)}$ Universitas Pakuan, Bogor, Indonesia \\ *e-mail korespondensi: rais.hidayat@unpak.ac.id
}

riwayat artikel : diterima: 24 November 2019; direvisi: 26 Desember 2019; disetujui: 16 Januari 2020

\begin{abstract}
Abstrak. Pada lembaga pondok pesantren, seni membaca Alquran menjadi salah satu kegiatan utama dalam pembelajaran, sekaligus menjadi ciri khas dan potensi keunggulan masing-masing lembaga yang menentukan kualitas lulusannya. Dibutuhkan manajemen pembelajaran membaca Alquran yang efektif agar tujuan pesantren tercapai. Penelitian ini fokus pada upaya menggali informasi secara mendalam dan komprehensif mengenai manajemen pembelajaran seni baca Alquran di Pondok Pesantren Alquran Al-Itqon Bogor. Penelitian menggunakan pendekatan kualitatif deskriptif analitis untuk menjabarkan, mendeskripsikan dan menganalisis secara objektif mengenai manajemen pembelajaran seni baca Alquran di Pondok Pesantren Alquran Al-Itqon Bogor. Pengumpulan data diperoleh melalui wawancara mendalam mengenai sub-fokus dari penelitian, yaitu tentang perencanaan, pengorganisasian, pelaksanaan dan evaluasi pembelajaran seni baca Alquran. Hasil penelitian menunjukan bahwa pengelolaan manajemen pembelajaran seni baca Alquran di Pondok Pesantren Alquran Al-Itqon dimulai langkah pertama perencanaan berupa: 1) penetapan tujuan, yaitu mencetak kader Qori-Qori'ah yang berkarakter Qur'ani, 2) penetapan program berupa program tahsin dan program tilawah, serta penetapan kurikulum berupa kurikulum khas pesantren. Langkah kedua, yaitu pengorganisasian berupa: 1) pembentukan kepengurusan pesantren yang terdiri dari pengurus santri putra dan pengurus santri putri, 2) pengaturan jadwal kegiatan pembelajaran tahsin dan tilawah yang dilaksanakan dua kali dalam sehari, 3) pengaturan ruangan serta alat yang digunakan dalam proses pembelajaran. Langkah ketiga yaitu pelaksanaan berupa: 1) tahapan-tahapan pelaksanaan pembelajaran, 2) pengalokasian waktu pembelajaran, 3) penggunaan metode serta media pembelajaran. Langkah terakhir yaitu evaluasi berupa: 1) penentuan tujuan evaluasi meliputi peningkatan kualitas bacaan, 2) pelaksanaan evaluasi meliputi perbaikan bacaan, dan 3) tindak lanjut hasil evaluasi meliputi pengulangan dan pemberian sertifikat lulusan.
\end{abstract}

Kata Kunci: Manajemen, Pembelajaran, Seni Baca Alquran

\section{LEARNING MANAGEMENT READ AL QURAN IN ALQURAN AL-ITQON BOARDING SCHOOL, BOGOR}

\begin{abstract}
The art of reading Alquran at boarding school is the major program that could be a uniqueness for the institution and the strengths as well. The excellent output of reading Alquran will support the achievement of the school target, therefore the school needs to develop effective learning management, especially in reading Alquran. This research is focused on learning management in the art of reading Alquran at Al-Itqon Islamic Boarding School Bogor. The study was using a descriptive qualitative analytical approach to describe, explain and analyze objectively about the learning management of reading Alquran at Al-Itqon Boarding School Bogor. The data was taken by interviews about the sub-focus of the research, which were: planning, organizing, implementing and evaluating. The results showed that the learning management of the art of reading Alquran at the Al-Itqon Islamic Boarding School in Bogor, begin with planning as the first step, that consist of:1) setting the goal of the program which is preparing student to be a Qori or Qoriah, 2) setting the main program, which are tahsin and recital. The second step is organizing which consists of 1) setting the organizational structure for both male and female students, 2) organizing the program schedule, 3) organizing the facilitation such, learning method and media. The third step is an implementation: 1) learning steps implementation, 2) allocation of learning schedule and duration, 3) media and learning method. The final step is evaluation, which is setting the evaluation objectives including improving reading quality, remedial, repetition by drilling and awarding graduate certificates
\end{abstract}

Keywords: Learning management, The art of reading Alquran

\section{PENDAHULUAN}

Dalam rangka pengembangan dan peningkatan kemampuan membaca Alquran dikalangan umat muslim, perlu diadakan kegiatan pembelajaran membaca Alquran yang efektif, mulai dari tingkat pemula hingga tahap mahir yang ditangani secara serius dan profesional. Oleh karena itu diperlukan upaya yang maksimal dalam manajemen pembelajaran seni baca Alquran.

Sebagai salah satu lembaga yang bergerak dalam pengembangan seni baca Alquran, Pondok Pesantren Alquran Al-Itqon Bogor menawarkan kepada masyarakat program untuk mempelajari seni baca Alquran dengan sistem pesantren. Dalam kiprahnya pada bidang pendidikan Alquran dilingkungan masyarakat, khususnya di Kabupaten Bogor, Pondok Pesantren Alquran Al-Itqon Bogor telah membuktikan eksistensi kualitasnya dengan sejumlah prestasi yang berhasil diraih oleh para 
santri maupun lulusannya dalam berbagai lomba tilawah Alquran, baik tingkat Kabupaten, Provinsi, Nasional, bahkan sampai tingkat Internasional.

Capaian prestasi para Qori dan Qori'ah hingga tingkat Nasional dan Internasional bukan hal yang mudah dicapai oleh lembaga-lembaga yang berkiprah dibidang pendidikan Alquran, dibutuhkan komitmen dalam menjajlankan manajemen pembelajaran yang efektif. Pondok Pesantren Alquran Al-Itqon Bogor melalui output para santri dan alumninya yang setiap tahun konsisten mengukir prestasi, adalah bukti implementasi manajemen pembelajaran membaca Alquran yang efektif, dan diharapkan dapat menjadi contoh best practice bagi lembaga serupa. Oleh karena itu dilakukan penelitian terkait manajemen pembelajaran seni baca Alquran di Pondok Pesantren Alquran Al-Itqon Bogor.

Rumusan mengenai manajemen dinyatakan Brantas (2009:4), sebagai suatu proses atau kerangka kerja yang melibatkan bimbingan atau pengarahan suatu kelompok orang ke arah tujuan-tujuan organisasional. Pengertian lebih rinci disampaikan Handoko (2015:10) bahwa manajemen adalah bekerja dengan orang-orang untuk menentukan, menginterpretasikan dan mencapai tujuan-tujuan organisasi dengan pelaksanaan fungsi-fungsi perencanaan (planning), pengorganisasian (organizing), penyusunan personalia atau kepegawaian (staffing), pengarahan dan kepemimpinan (leading), dan pengawasan (controlling).

Sejalan dengan rumusan Handoko (2015:2) menyatakan bahwa manajemen adalah ilmu dan seni yang terdiri atas perencanaan, pengorganisasian, pengarahan dan pengawasan terhadap kinerja organisasi dengan menggunakan sumber daya yang dimiliki untuk mencapai tujuan dan sasaran organisasi. Menurut Robbins dan Coulter (Karyoto, 2015:3) manajemen adalah aktivitas kerja yang melibatkan koordinasi dan pengawasan terhadap pekerjaan orang lain sehingga pekerjaan tersebut dapat diselesaikan secara efektif dan efisien. Mochtar (Zaniarti,2014:49) manajemen adalah mengetahui kemana yang dituju, kesukaran apa yang harus dihindari, kekuatan-kekuatan apa yang dijalankan dan bagaimana mengemudikan kapal dengan sebaik-baiknya tanpa pemborosan waktu dalam proses mengerjakannya.

Berdasarkan pada paparan, maka dapat disintesiskan bahwa manajemen merupakan serangkaian kegiatan yang berkesinambungan terkait dengan apa yang diinginkan, siapa dan bagaimana penempatan sumber daya manusia serta sarana pendukungnya, siapa yang melaksanakan dan bagaimana pelaksanaannya, serta siapa yang mengawasi dan bagaimana pengawasannya yang kesemuanya itu dilakukan oleh seorang atau kelompok guna mencapai tujuan yang telah ditetapkan.

Pengertian hakikat pembelajaran yang mengarah pada unsur-unsurnya dikemukakan Hamalik (2003:57), yaitu suatu kombinasi yang tersusun, meliputi unsur-unsur manusiawi, material, fasilitas, perlengkapan, dan prosedur yang saling mempengaruhi mencapai tujuan pembelajaran.

Sedangkan Suyudi (2005:122) menekankan pada makna aktivitas pembelajaran, yaitu proses untuk memperoleh pengetahuan, sedangkan pengetahuan adalah salah satu cara untuk memperoleh kebenaran atau nilai, sementara kebenaran adalah pernyataan tanpa keragu-raguan yang dimulai dengan adanya sikap keraguan terlebih dahulu. Pendapat ini selaras dengan pernyataan Saefudin dan Berdiati (2014:8) bahwa pembelajaran secara harfiah berarti proses belajar. Pembelajaran dapat dimaknai sebagai proses penambahan pengetahuan dan wawasan melalui rangkaian aktivitas yang dilakukan secara sadar oleh seseorang dan mengakibatkan perubahan dalam dirinya, sehingga terjadi perubahan yang sifatnya positif, dan pada tahap akhir akan didapat keterampilan, kecakapan dan pengetahuan baru. Sedangkan Sanjaya (2008:78) menjelasakan pembelajaran sebagai proses pengaturan lingkungan yang diarahkan untuk mengubah perilaku siswa ke arah yang positif dan lebih baik, sesuai dengan potensi dan perbedaan yang dimiliki siswa

Demikian pula pendapat Gagne (Benny,2009:9) yang menekankan pembelajaran pada kegiatan, yaitu serangkaian aktivitas yang sengaja diciptakan dengan maksud untuk memudahkan terjadinya proses belajar. Winkel (Saefuddin, 2014:9) merumuskan pembelajaran sebagai seperangkat tindakan yang dirancang untuk mendukung proses belajar peserta didik, dengan memperhitungkan kejadian-kejadian eksternal yang berperan terhadap kejadian-kejadian internal yang berlangsung didalam peserta didik Dari beberapa pendapat tentang pengertian pembelajaran dapat disintesiskan bahwa pembelajaran adalah suatu proses yang tersusun dan terencana yang meliputi unsur-unsur manusiawi, material, fasilitas, perlengkapan dan prosedur yang saling mempengaruhi untuk memperoleh pengetahuan guna mencapai perubahan tingkah laku ke arah yang lebih baik.

Seni baca Alquran dikalangan para Qori dikenal dengan istilah Naghom Alquran. Menurut Syahid (2006:18) istilah Naghamul Quran berasal dari kata نغم jama'nya انغاغيم dan, kemudian dirangkai dengan Alquran menjadi نغم النران yang artinya adalah melagukan Alquran, juga disebut sebagai تحسين الصوت atau membaguskan suara dalam membaca Alquran. Istilah nagham juga dikhususkan untuk tilawah Alquran, kemudian di Indonesia terkenal dengan sebutan seni baca Alquran. Berdasarakan hal ini dapat dikatakan bahwa yang dimaksud dengan Nagham Alquran adalah ragam intonasi yang indah yang disuarakan dalam bacaan Alquran, dapat juga dikatakan sebagai alunan suara yang indah dalam nada, baik mulai dari rendah, menengah, tinggi dan tertinggi bahkan dengan tambahan nada.

Dalam bahasa Arab, selain kata an-nagham atau an-naghamah yang berarti lagu, terdapat juga sejumlah kata padanannya atau sinonimnya. Antara lain seperti kata al-lahnu, tarannum atau tarnim dan al-ghina. Kata al-lahnu ditemui dalam bahasa arab seperti lahana fil qira'ah yang berarti tarannama fiiha (melagukan suatu bacaan) dan lahanal anaasyida yang berarti wadha'a lahaa al-haanan tughanna biha (membuat sejumlah lagu untuk syair-syair yang disenandungkannya).

Dari penjelasan tersebut dapat diketahui bahwa padanan kata atau sinonim kata nagham adalah kata talhin atau lahn, tarannum atau tarnim dan al-gina. Padanan dengan kata nagham yang ada kaitannya dengan Alquran adalah kata lahn dan tarannum atau tarnim. Sebagaimana ketiga kata tersebut sering digunakan untuk istilah "Seni Baca Alquran", seperti القران, ترنم القران dan تلحين القرأن. 
Mengenai persamaan penggunaan ketiga istilah tersebut diatas, para pakar Dzawil Ashwat (mempunyai suara indah) seperti Abduh as-Shu'udi, Azra'I Abdurrauf, dan Mukhtar Luthfi al-Anshary mempertegas pengertian istilah-istilah tersebut sebagai berikut;

1. Nagham (نغر) ialah vokal suara indah tunggal (tanpa diiringi alat musik) dan tidak terikat dengan not balok serta khusus dipergunakan untuk Tazyiinusshouti Bitilawatil Quran yang berarti membaguskan suara dalam membaca Alquran.

2. Talhin (تلحين) yaitu vokal suara indah dan tunggal yang 'arabiyy Alquran, ada yang terkait dengan not balok, sehingga bisa dipergunakan untuk selain Alquran, seperti Qasidah, Nasyid dan lain-lain.

3. Tarannum (ترنم) ialah vokal suara indah Alquran, namun suara ini ada juga yang mempergunakan alat musik, sehingga banyak terkait oleh not balok. Disinilah timbul istilah tausyikh bagi orang yang mempelajari seni baca Alquran, karena kebanyakan tausyikh itu terkait dengan not-not yang telah tersusun.

Berdasarkan pemaparan mengenai istilah-istilah yang berkaitan dengan seni baca Alquran, maka dapat disimpulkan bahwa seni baca Alquran adalah seni dalam membaca Alquran yang sesuai dengan kaidah ilmu tajwid dan diperindah oleh suara serta irama dan lagu-lagu Alquran.

\section{METODE PENELITIAN}

Penelitian dilaksanakan menggunakan pendekatan kualitatif deskriptif analitis dengan cara menjabarkan, mendeskripsikan dan menganalisa secara objektif mengenai manajemen pembelajaran seni baca Alquran di Pondok Pesantren Alquran Al-Itqon Bogor. Penelitian ini mengkaji dan menggali informasi secara mendalam dan komprehensif melalui wawancara terhadap empat sub-fokus dari penelitian, yaitu tentang perencanaan, pengorganisasian, pelaksanaan dan evaluasi pembelajaran seni baca Alquran di Pondok Pesantren Alquran Al-Itqon Bogor. Subfokus-subfokus penelitian dirumuskan pada beberapa pertanyaan berikut: Bagaimana perencanaan pembelajaran seni baca Alquran di Pondok Pesantren Alquran Al-Itqon Bogor? Bagaimana pengorganisasian pembelajaran seni baca Alquran di Pondok Pesantren Alquran Al-Itqon Bogor? Bagaimana pelaksanaan pembelajaran seni baca Alquran di Pondok Pesantren Alquran Al-Itqon Bogor? dan Bagaimana Evaluasi pembelajaran seni baca Alquran di Pondok Pesantren Alquran Al-Itqon Bogor?

\section{HASIL DAN PEMBAHASAN}

Sub Fokus 1: Perencanaan pembelajaran seni baca Alquran di Pondok Pesantren Alquran Al-Itqon Bogor.

Pembelajaran seni baca Alquran di Pondok Pesantren Alquran Al-Itqon bertujuan untuk meningkatkan kualitas para santri dalam membaca Alquran sehingga para santri memiliki kemampuan membaca Alquran yang sesuai dengan kaidah ilmu tajwid serta mampu mengkhatamkan bacaan Alquran 30 juz melalui program tahsin agar bacaannya dapat dipertanggung jawabkan dan memiliki sanad yang jelas. Selain itu para santri diharapkan mampu menjadi qari atau qari'ah yang handal dalam melantunkan ayat-ayat suci Alquran. Untuk mencapai tujuan tersebut perencanaan terkait pembelajaran seni baca Alquran dibagi ke dalam dua program, yaitu program tahsin dan program tilawah. Kedua program tersebut ditangani oleh pengasuh pesantren dengan dibantu oleh asisten atau staf tenaga pengajar yang sudah ditunjuk oleh pengasuh pesantren.

Kurikulum yang digunakan merupakan kurikulum khas pesantren yang dibuat oleh Pengasuh Pesantren, kurikulumnya tidak terikat oleh aturan-aturan program pembelajaran seperti pada umumnya seperti harus adanya RPP dan silabus. Akan tetapi dalam pelaksanaannya tetap memuat kegiatan muqoddimah, kegiatan inti dan kegiatan penutup.

\section{Sub Fokus 2: Pengorganisasian pembelajaran seni baca Alquran di Pondok Pesantren Alquran Al-Itqon Bogor}

Pengorganisasian pembelajaran seni baca Alquran berada dibawah kendali pengasuh pondok pesantren, melalui pembentukan kepengurusan pondok pesantren dan pengangkatan asisten atau staf pengajar. Pengurus pondok pesantren terdiri dari pengurus putra dan pengurus putri yang meliputi rois, roisah, sekertaris, bendahara, seksi pendidikan, seksi peribadahan, seksi kebersihan, seksi keamanan dan seksi kesehatan, dan humas. Masing-masing pengurus bertanggung jawab kepada rois dan roisah untuk dikoordinasikan kepada pengasuh pondok pesantren. Pengaturan dan pembagian jadwal kegiatan pondok pesantren dibuat oleh pengasuh pesantren, dibantu oleh para pengurus. Pengurus dan asisten atau staf pengajar bertanggungjawab untuk mengaktifkan seluruh kegiatan pembelajaran seni baca Alquran baik program tahsin maupun program tilawah atau mujawwad.

Kegiatan pembelajaran program tahsin dilaksanakan dua kali dalam sehari, yaitu pagi hari setelah sholat shubuh dan siang hari setelah sholat dzuhur, masing-masing dilaksanakan di Aula untuk santri putri dan di Masjid untuk santri putra. Sedangkan program tilawah dilaksanakan sore hari setelah sholat ashar dan malam hari setelah sholat isya dilaksanakan di Aula dengan menggunakan peralatan atau media pembelajaran berupa pengeras suara.

\section{Sub Fokus 3: Pelaksanaan pembelajaran seni baca Alquran di Pondok Pesantren Alquran Al-Itqon Bogor}

Teknik pelaksanaan program tahsin adalah setiap santri dilatih satu persatu oleh tenaga pengajar untuk membaca ayat Alquran sesuai dengan hanca atau lanjutan ayat. Apabila terdapat kesalahan membaca, staf pengajar langsung memperbaiki. Program tilawah dilaksanakan dengan cara berjamaah dimana seluruh santri, santri putra maupun putri berkumpul bersama di 
Aula dengan diajar oleh seorang tenaga pengajar menggunakan metode demonstrasi, yang kegiatan pembelajarannya terpusat pada guru. Guru mencontohkan bacaan ayat Alquran dengan berirama atau bernada diikuti seluruh santri untuk menirukan bacaan guru.

Alokasi waktu yang digunakan dalam proses pembelajaran pada program tahsin berkisar antara 5 sampai 10 menit untuk setiap masing-masing santri. Sedangkan program tilawah dilaksanakan selama 1 sampai 1,5 jam untuk setiap pertemuan. Metode yang digunakan dalam pembelajaran seni baca Alquran program tahsin adalah metode talaqqi musyafahah. Sedangkan pada program tilawah adalah metode demonstrasi. Selanjutnya media yang biasa digunakan dalam pelaksanaan pembelajaran adalah pengeras suara, tape recorder dan meja rekal untuk alas Alquran.

\section{Sub Fokus 4: Evaluasi pembelajaran seni baca Alquran di Pondok Pesantren Alquran Al-Itqon Bogor}

Tujuan evaluasi pembelajaran adalah untuk mengetahui kemampuan membaca Alquran, dan meningkatkan kualitas bacaan Alquran bagi para santri. Para santri diharapkan dapat mengajarkannya kembali kepada masyarakat luas setelah dinyatakan lulus dari pesantren dengan kualitas bacaan yang dapat dipertanggungjawabkan.

Evaluasi dilaksanakan pada saat kegiatan pembelajaran atau pengajian berlangsung, dengan perbaikan langsung kesalahan bacaan yang dilakukan oleh para santri oleh pengagjar, dengan memberi contoh bacaan yang benar, lalu dibaca ulang oleh santri sampai bacaannya dinyatakan benar. Santri yang memiliki keahlian khusus dibidang tilawah biasanya diikutsertakan dalam ajang Musabaqoh Tilawatil Qur'an baik tingkat Kabupaten, Provinsi, Nasional bahkan sampai Internasional. Hal ini dilaksanakan untuk memacu semangat para santri dalam mempelajarai dan memperdalam ilmu Alquran.

Tindak lanjut bagi santri yang belum bagus bacaannya adalah dengan terus mengulang sampai bacaannya dianggap bagus oleh tenaga pengajar dan dinyatakan khatam atau lulus dari pesantren.

\section{SIMPULAN}

Berdasarkan hasil penelitian kualitatif deskriptif analitik tentang manajemen pembelajaran seni baca Alquran di Pondok Pesantren Alquran Al-Itqon Bogor diperoleh kesimpulan sebagai berikut:

1. Perencanaan pembelajaran seni baca Alquran di Pondok Pesantren Alquran Al-Itqon Kabupaten Bogor mencakup tentang tujuan, program pembelajaran dan kurikulum, yaitu;

a. Tujuan pembelajaran adalah para santri memiliki kemampuan membaca Alquran sesuai dengan kaidah ilmu tajwid serta khatam bacaan Alquran 30 juz melalui program tahsin agar bacaannya dapat dipertanggung jawabkan dan memiliki sanad yang jelas. Selain itu, mampu melantunkan ayat suci Alquran dengan suara atau nada yang indah. Agar menambah kecintaan terhadap Alquran, sehingga mampu memacu semangat untuk terus memperdalam dan mengamalkan isi kandungan Alquran dan menjadi insan yang berkarakter Qur'ani.

b. Pembelajaran seni baca Alquran dibagi kedalam dua program yaitu program tahsin atau musyafahah dan program tilawah atau mujawwad.

c. Kurikulum yang digunakan adalah kurikulum khas pesantren yang dibuat oleh Pengasuh Pondok Pesantren yang tidak terikat oleh aturan-aturan program pembelajaran seperti pada umumnya seperti harus adanya RPP dan silabus. Akan tetapi dalam pelaksanaannya tetap memuat kegiatan muqoddimah, kegiatan inti dan kegiatan penutup.

2. Pengorganisasian pembelajaran seni baca Alquran di Pondok Pesantren Alquran Al-Itqon Bogor mencakup tentang pembentukan pengurus, pengaturan jadwal, pengaturan ruang dan pengaturan ketersediaan alat atau media pembelajaran, yaitu:

a. Pembentukan pengurus santri putra dan santri putri berada dibawah kendali pengasuh pondok pesantren, karena merupakan hak atau kewenangan Pengasuh Pesantren.

b. Pengaturan dan pembagian jadwal kegiatan pondok pesantren dibuat oleh pengasuh pesantren dibantu oleh para pengurus yang sudah dibentuk.

c. Ruang yang digunakan untuk pembelajaran program tahsin adalah di Aula untuk santri putri, dan di Masjid untuk santri putra. Sedangkan untuk program tilawah adalah di Aula

d. Ketersediaan alat atau media pembelajaran seperti speaker aktif atau pengeras suara, tape recorder dan meja lekar terpenuhi.

3. Pelaksanaan pembelajaran seni baca Alquran di Pondok Pesantren Alquran Al-Itqon Kabupaten Bogor mencakup tahapan kegiatan, alokasi waktu, penggunaan metode dan penggunaan media pembelajaran, yaitu:

a. Tahapan kegiatan pelaksanaan pembelajaran seni baca Alquran meliputi kegiatan pembuka, kegiatan inti dan kegiatan penutup. 
b. Alokasi waktu pada program tahsin berkisar antara 5 sampai 10 menit untuk masing-masing santri. sedangkan pada program tilawah adalah berkisar antara 1 sampai $1 \frac{1 / 2}{2}$ jam dalam setiap pertemuannya untuk seluruh santri.

c. Metode yang digunakan dalam pembelajaran seni baca Alquran program tahsin adalah metode talaqqi musyafahah. Sedangkan pada program tilawah adalah metode demonstrasi atau boleh dibilang metode talaqqi musyafahah secara berjamaah.

d. Media yang biasa digunakan dalam pelaksanaan pembelajaran adalah media alat berupa speaker aktif atau pengeras suara, perekam suara atau tape recorder dan meja lekar untuk alas Alquran.

4. Evaluasi pembelajaran seni baca Alquran di Pondok Pesantren Alquran Al-Itqon Bogor mencakup tentang tujuan, pelaksanaan evaluasi dan tindak lanjut, yaitu:

a. Tujuan dari evaluasi pembelajaran adalah untuk mengetahui kemampuan membaca Alquran dan untuk meningkatkan kualitas bacaan Alquran bagi para santri.

b. Pelaksanaan evaluasi dilaksanakan secara langsung yaitu pada saat kegiatan pembelajaran atau pengajian berlangsung. Tindak lanjut bagi santri yang belum bagus bacaannya adalah dengan terus mengulang sampai bacaannya dianggap bagus oleh tenaga pengajar dan dinyatakan khatam atau lulus dari pesantren.

\section{REFERENSI}

Benny A. Pribadi, (2009) Model Desain Sistem Pembelajaran, Jakarta: Dian Rakyat

Brantas. (2009) Dasar-Dasar Manajemen. Bandung: Alfabeta.

Hamalik, Oemar. (2003) Kurikulum dan Pembelajaran, Jakarta: Bumi Aksara.

Handoko, T.Hani. (2015) Manajemen Edisi 2. Yogyakarta: BPFE

Karyoto. (2015) Dasar-dasar Manajemen Teori, Definisi, dan Konsep. Yogyakarta: ANDI

Saefuddin, Asis dan Berdiati, Ika. (2014). Pembelajaran Efektif. Bandung: Pt Remaja Rosdakarya.

Sanjaya, Wina, (2008) Pembelajaran Dalam Implementasi Kurikulum Berbasis Kompetensi, Jakarta: Kencana

Suyudi. (2005) Pendidikan Dalam Perspektif Alquran, Yogyakarta : Mikroj.

Syahid, Ahmad (2006) Sejarah dan Pengantar Ilmu Nagham, Jakarta: Pengurus Pusat JQH.

Zainarti. (2014) Manajemen Islami Perspektif Al-Qur'an. Jurnal Iqra'. Volume 01. Diakses 24 Oktober 2019 